\title{
A probabilistic approach to rainwater harvesting systems design and evaluation
}

\author{
Ming-Daw Su ${ }^{a}$, Chun-Hung Lin ${ }^{a}$, Ling-Fang Chang ${ }^{a}$, Jui-Lin Kang ${ }^{b}$, Mei-Chun Lin ${ }^{\mathrm{a}, *}$ \\ a Dept. of Bioenvironmental Systems Engineering, National Taiwan University, No. 1, Sec. 4, Roosevelt Rd., Taipei, 10617, Taiwan \\ ${ }^{\mathrm{b}}$ Atmospheric Sciences Mesoscale Research Lab, National Taiwan University, Taipei, Taiwan
}

\section{A R T I C L E I N F O}

\section{Article history:}

Received 27 March 2008

Received in revised form

12 November 2008

Accepted 11 March 2009

Available online 16 April 2009

\section{Keywords:}

Rainwater harvesting systems

Simulation

Probability distribution

Storage capacity

\begin{abstract}
A B S T R A C T
Although rainwater harvesting system (RHS) is an effective alternative to water supply, its efficiency is often heavily influenced by temporal distribution of rainfall and water demand. Since natural precipitation is a random process and has probabilistic characteristics, it will be more appropriate to describe these probabilistic features of rainfall and its relationship with design storage capacity as well as supply deficit of RHS. This paper aims at developing a methodology for establishing the probabilistic relationship between storage capacities and deficit rates of RHS. A simulation model was built to simulate the input rainfall and water release in RHS. Historical rainfall records were then used as input for simulation and the results were used in probabilistic analysis for establishing the relationships between storage capacities and water supply deficits. The city of Taipei was used as study area for demonstration of this methodology and probabilistic distribution curves for storage capacity and deficit rate relationships were presented. As a result, a set of curves describing the continuous relationships between storage capacities and deficit rates under different exceedance probabilities were generated as references to RHS storage design. At a chose exceedance probability of failure, the engineer can decide from the curve on the storage size under a preset deficit rate.
\end{abstract}

Crown Copyright (c) 2009 Published by Elsevier B.V. All rights reserved.

\section{Introduction}

Rainfall is the most directly accessible water supply source. Storages are usually needed for regulating non-uniformly distributed characteristics of rainfall among spatial and temporal aspects. Other than large reservoirs, small on-site rainwater harvesting systems (RHSs) have been successfully implemented as alternative water supply sources in some countries like Japan, Hong Kong, Singapore, and the United States (Thomas, 1998; Hatibu and Mahoo, 1999; Li et al., 2000). Rainwater harvesting systems intercept rainwater in hydrologic cycle through either natural landforms or artificial facilities. The small scale RHS does not involve the existing water right. And it has become one of the economical and practical measures for providing supplementary water supplies with its easy system installation. It can be a supplementary water source in urbanized regions for miscellaneous household uses such as toilet flushing, lawn watering, landscape and ecological pools, and cooling for air conditioning (Handia et al., 2003). It may even serve as a major water supply source in some rural or less-developed areas (Thomas, 1998; Liaw and Tsai, 2004). Other than storing water during rainfall period for later uses, it is also capable of providing some detention capacity for flood attenuations in some regions (Becker and

\footnotetext{
* Corresponding author. Tel.: +886 23366 3451; fax: +88622363 5854

E-mail address: madgebse@gmail.com (M.-C. Lin).
}

Raasch, 2003; Kumar et al., 2005). Rainwater harvesting system has been regarded as a sound strategy of alternative water sources for increasing water supply capacities (Hatibu and Mahoo, 1999; Motsi et al., 2004).

The efficiency of RHS is largely affected by the distribution patterns of rainfall as well as those of water demands. Although optimization (Zhang and Cai, 2003; Wei et al., 2005) and simulation (Jenkins and Lund, 2000; Srivastava, 2001; Liaw and Tsai, 2004; Panigrahi et al., 2005) approaches have both been used for storage capacity design studies, most of these studies described the relationship between storages and deficit rates by means of classical probability approaches. The results were mostly presented as deficit variation under some fixed storage capacities (Rahman and Yusuf, 2000; Panigrahi et al., 2007; Machiwal et al., 2004; Motsi et al., 2004; Yue and Wang, 2004; Ngigi et al., 2005) or as average deficits varied with storage capacities (Rahman and Yusuf, 2000; Qian et al., 2004; Akintug and Rasmussen, 2005; Negri et al., 2005). Since there exists continuous probabilistic relationships between storage capacities and supply deficits, these discrete descriptions of storages and deficits are not realistically applicable for RHS designs.

This study aims at establishing a methodological framework for developing continuous representation for probabilistic relationships between storage capacities and deficit rates. The water supply and demand data of Taipei metropolitan were used as study examples for this framework development. A simulation approach is applied to study the feasibility of substituting rainwater harvest for toilet flushing water on a single building basis. It concludes with the 
presentations of probabilistic distribution curves for storage capacity and deficit rate relationships. It is hoped that this methodology and the results can serve as references to RHS storage design in the future.

\section{Methodology}

The major goal of this study is to establish the probabilistic relationships between RHS storage capacities and water supply deficit rates. An annual simulation model, as depicted in Fig. 1, was built for this purpose. A mass balance equation was incorporated into the model to simulate the storage capacity operation with a standard operating policy (SOP rule) for the RHS to supply water to meet the demand as much as possible in each operating periods. Fifty years of daily rainfall data were fed into the model to estimate water supply deficits. The simulation results were then used as the basis for probabilistic study on the relationships between storage capacities and deficit rates.

\subsection{Simulation model}

The physical process of a system can be described through repeated system operations with preset parameters and an array of input data. System characteristics and behaviors can be better understood through this simulation process. System simulation can be used to evaluate alternatives. The impacts of alternatives can be revealed to decision makers through what-if studies. Satisfied solutions instead of optimal ones are achieved through system simulation and this scenario-based decision process (Nandalal and Sakthivadivel, 2002; Rajasekaram et al., 2003).

In the mass balance computation for the storage capacity, rainfall is regarded as inflow and the release as well as possible spill as outflow. Decisions on releases are based on the SOP rule that the demand will be met in each operating periods as far as the storage is available. Rainfall data from 1953 to 2002 were used to estimate the inflows to the storage tank, and the releases were estimated by

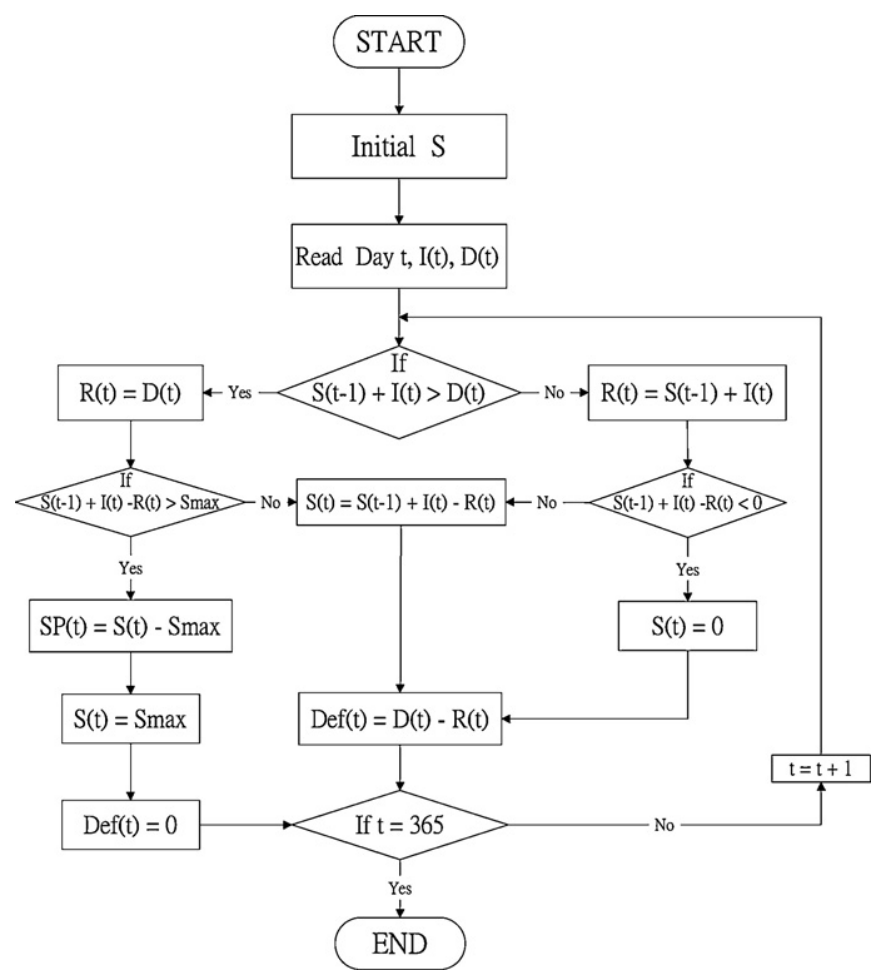

Fig. 1. Flowchart for simulation model. using the following equation:

$R_{t}= \begin{cases}D_{t} & \text { if } I_{t}+S_{t-1} \geq D_{t} \\ I_{t}+S_{t-1} & \text { if } I_{t}+S_{t-1}<D_{t}\end{cases}$

where $t$ subscript is the day and $D_{t}$ is the daily demand $\left(\mathrm{m}^{3}\right) ; S_{t-1}$ is the tank storage at the end of the previous day $\left(\mathrm{m}^{3}\right) ; R_{t}$ and $I_{t}$ are the release and the inflow, respectively in $\mathrm{m}^{3}$. The spill in day $t$ can be determined based on Eq. (2). Spill occurs with an amount equal to the difference between the residual storage and design maximum tank capacity as the residual water after release exceeds the maximum storage capacity, and there will be no spill otherwise.

$S P_{t}= \begin{cases}I_{t}+S_{t-1}-D_{t}-S_{M A X} & \text { if } I_{t}+S_{t-1}-D_{t}>S_{M A X} \\ 0 & \text { if } I_{t}+S_{t-1}-D_{t} \leq S_{M A X}\end{cases}$

$S_{t}$, tank storage at the end of day $t$, can then be determined using the following equation:

$S_{t}= \begin{cases}S_{M A X} & \text { if } S P_{t}>0 \\ S_{t-1}+I_{t}-R_{t} & \text { if } S P_{t} \leq 0\end{cases}$

where $S P_{t}$ is the spill $\left(\mathrm{m}^{3}\right)$ and $S_{\text {MAX }}$ is the design storage capacity $\left(\mathrm{m}^{3}\right)$.

The demand may not always be fulfilled by this SOP rule. Deficit may occur whenever the release $R_{t}$ is smaller than demand $D_{t}$. The deficit at day $t, D e f_{t}$, can be determined by the difference between $D_{t}$ and $R_{t}$. The annual deficit rate $(D R)$ can be defined as the ratio of total deficit volume to total demand as shown in the following equation:

$$
\begin{aligned}
D R & =\frac{\sum D e f_{t}}{\sum D_{t}} \\
= & \frac{\sum(D t-R t)}{\sum D_{t}}
\end{aligned}
$$

\subsection{Probabilistic model}

The probabilistic relationships between storage capacities and deficit rates can be developed from the simulation results based on the historical rainfall records. The deficit rate will be a random variable since it was generate from the simulation with natural rainfall which is a continuous random variable. There exists some probability distribution, for example, the normal distribution (Rahman and Yusuf, 2000; Surendran et al., 2005) or the lognormal distribution (Xu and Goulter, 1999; Surendran et al., 2005) for deficit rate under a specific design tank storage. As shown in Fig. 2(a), probability density functions (pdf) of deficit rate can be established for each design storage capacities from the simulation results. The cumulative probability functions (CDF) of deficit rates can then be constructed by integrating the pdf. The CDFs can then be transformed into the exceedance probability (EP) curves as shown in Fig. 2(b). And for a specific exceedance probability $\mathrm{EP}_{i}$, a curve like the one shown in Fig. 2(c) can be established to describe the relationship between the design storage capacity and the corresponding deficit rate. These relationships can be used by engineers in the design process. At a chosen exceedance probability of failure, the engineer can decide from the curve on the storage size under a preset deficit rate. This more comprehensive perspective of the design storage-deficit rate is more realistically applicable than traditional presentation of deficit rate distribution under specific design storage.

\section{Study area}

For exploring these probabilistic relationships between RHS storage capacities and water supply deficit rates, City of Taipei was 

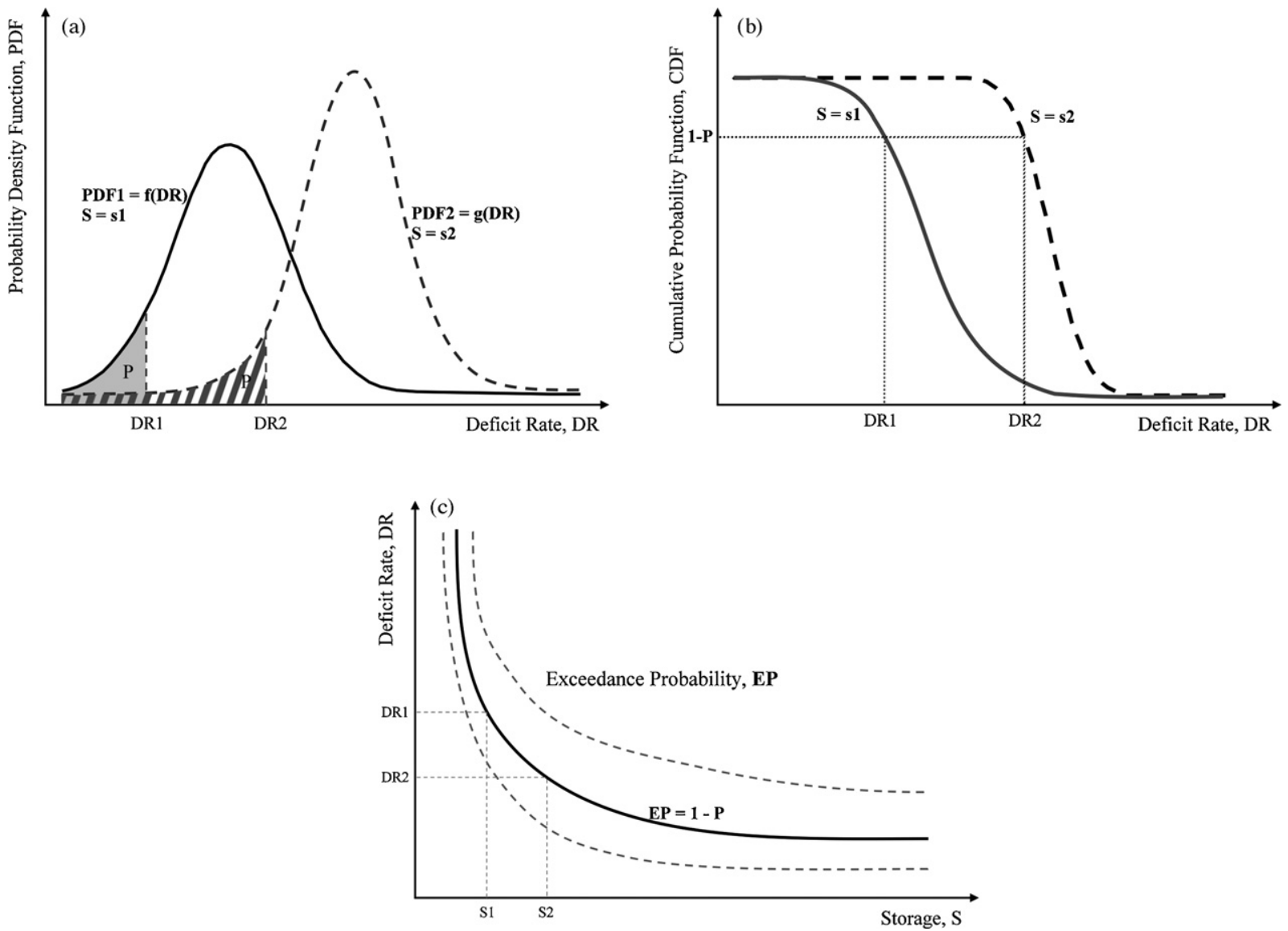

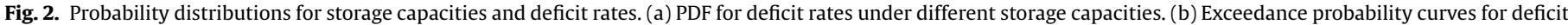
rates under different storage capacities. (c) Relationships between storage capacities and deficit rates.

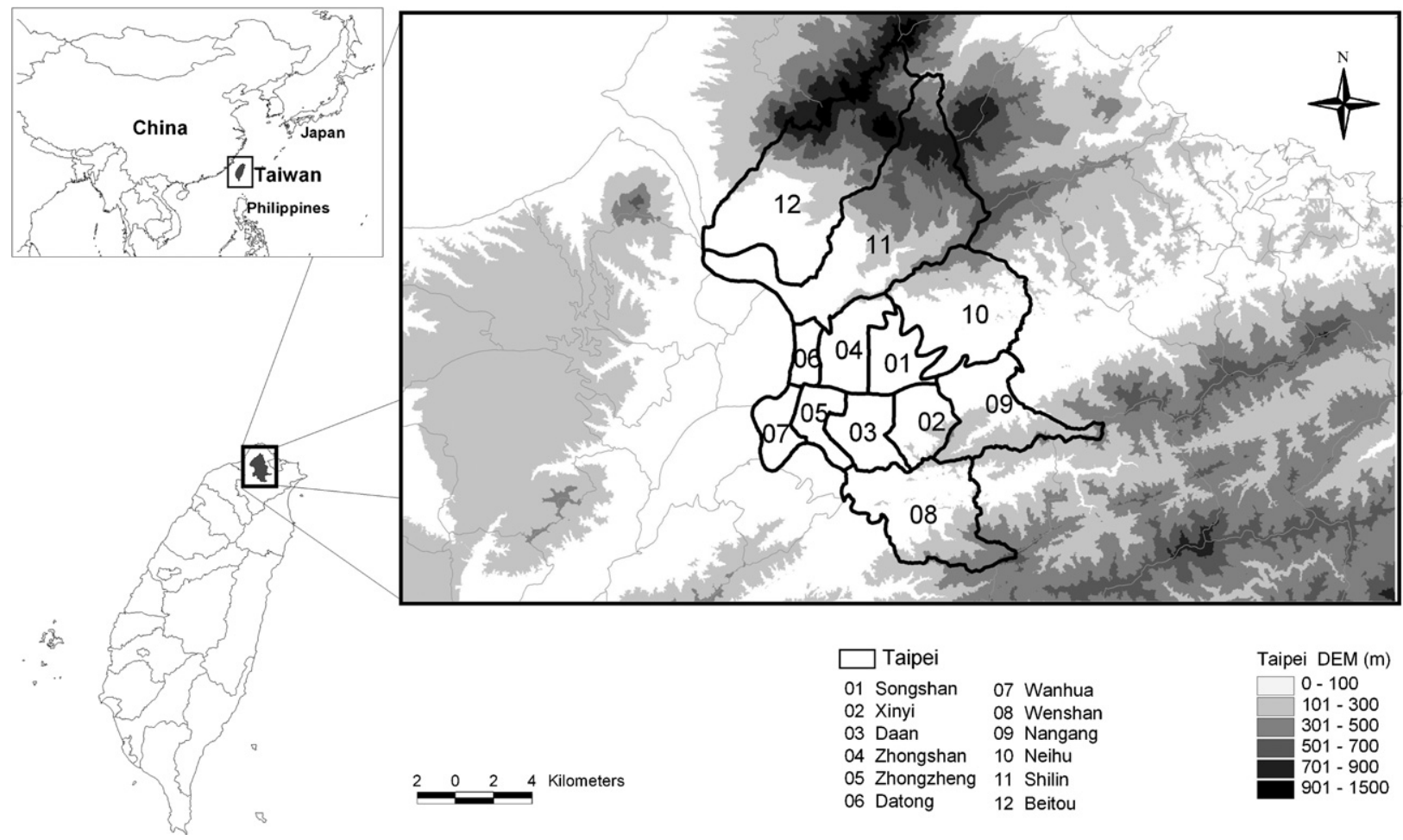

Fig. 3. Topography of Taipei City. 
Table 1

Elevation and building density in Taipei.

\begin{tabular}{|c|c|c|c|c|c|}
\hline & Township & Average elevation (m) & Area (ha) & No. of buildings & No. of building per ha \\
\hline 01 & Songshan & 4.3 & 929 & 6,000 & 6.46 \\
\hline 02 & Xinyi & 81.9 & 1121 & 10,190 & 9.09 \\
\hline 03 & Daan & 46.3 & 1136 & 14,229 & 12.52 \\
\hline 04 & Zhongshan & 42.3 & 1368 & 10,908 & 7.97 \\
\hline 05 & Zhongzheng & 8.2 & 761 & 12,115 & 15.93 \\
\hline 06 & Datong & 3.7 & 568 & 7,386 & 13.00 \\
\hline 07 & Wanhua & 4.4 & 885 & 9,966 & 11.26 \\
\hline 08 & Wenshan & 144.4 & 3151 & 10,183 & 3.23 \\
\hline 09 & Nangang & 135.6 & 2184 & 4,784 & 2.19 \\
\hline 10 & Neihu & 115.8 & 3158 & 8,365 & 2.65 \\
\hline 11 & Shihlin & 378.1 & 6237 & 18,743 & 3.01 \\
\hline 12 & Beitou & 444.1 & 5682 & 16,160 & 2.84 \\
\hline
\end{tabular}

selected as the study target. The feasibility of substituting stored rainwater for toilet flushing was examined through a system simulation model as described above. There are total 12 townships in Taipei city as shown in Fig. 3. Most of the land in the study area is flat, of which $68 \%$ of elevation is less than $300 \mathrm{~m}$ and $17 \%$ of those are above $500 \mathrm{~m}$.

As shown in Fig. 3 and Table 1, among the 12 townships of Taipei City, Songshan(01), Xinyi(02), Daan(03), Zhongshan(04), Zhongzheng(05), Datong(06) and Wanhua(07) townships have higher density of buildings and also are flatter in topography. This highly urbanized area was used as study target in this paper.

\subsection{Building rooftop area}

In the study area, according to the building statistics from the city government of Taipei (Dept. of Land, 2005), there are about $58 \%$ of the buildings having a rooftop area less than $150 \mathrm{~m}^{2}$. This number of $150 \mathrm{~m}^{2}$ was then adopted as the average roof top area per building. Daily volume of rainwater that can be caught and stored can be estimated using the following equation:

$V_{t}=\frac{I_{t}}{1000} \times A$

where $V_{t}$ is the daily volume of rainwater in $\mathrm{m}^{3} /$ day; $I_{t}$ is the daily rainfall in $\mathrm{mm} /$ day; $A$ is the collection area in $\mathrm{m}^{2}$; and 1000 is the conversion factor from liters to $\mathrm{m}^{3}$.

\subsection{Rainfall data}

There are about 30 rain gauge stations in Taipei metropolitan area. To facilitate the system simulation process for probabilistic study, the longer the record length, the more realistic the results will be. It was suggested that at least 50 years of rainfall data is appropriate for display of long-term trend (Liaw and Tsai, 2004). Thiessen polygons are constructed for all the gauge stations with record length longer than 50 years as shown in Fig. 4. The data recorded at Taipei rain gauge station was selected as rainfall input data because its control area covers almost the whole study area. As shown in Fig. 5, the rainfall records with a length of 50 years (1953-2002) have an annual average of $2215 \mathrm{~mm}$ and a standard deviation of $519 \mathrm{~mm}$. There exists a rather non-uniform monthly distribution as shown in Fig. 6 with about 55\% of rainfall concentrated from June to September. The storage facilities are required for this region to achieve adequate and steady water supply.

\subsection{Water demand for toilet flushing}

According to the statistical data of Taipei City Government (Dept. of Land, 2005), the average person per building is about 21.34 in the study area, representing a multiple family living style in the highrises. From the analysis of Industrial Technology Research Institute, Taiwan (Hwang et al., 2003), the water consumption per capita per day is estimated as 2501 in Taipei city. Toilet flushing accounts

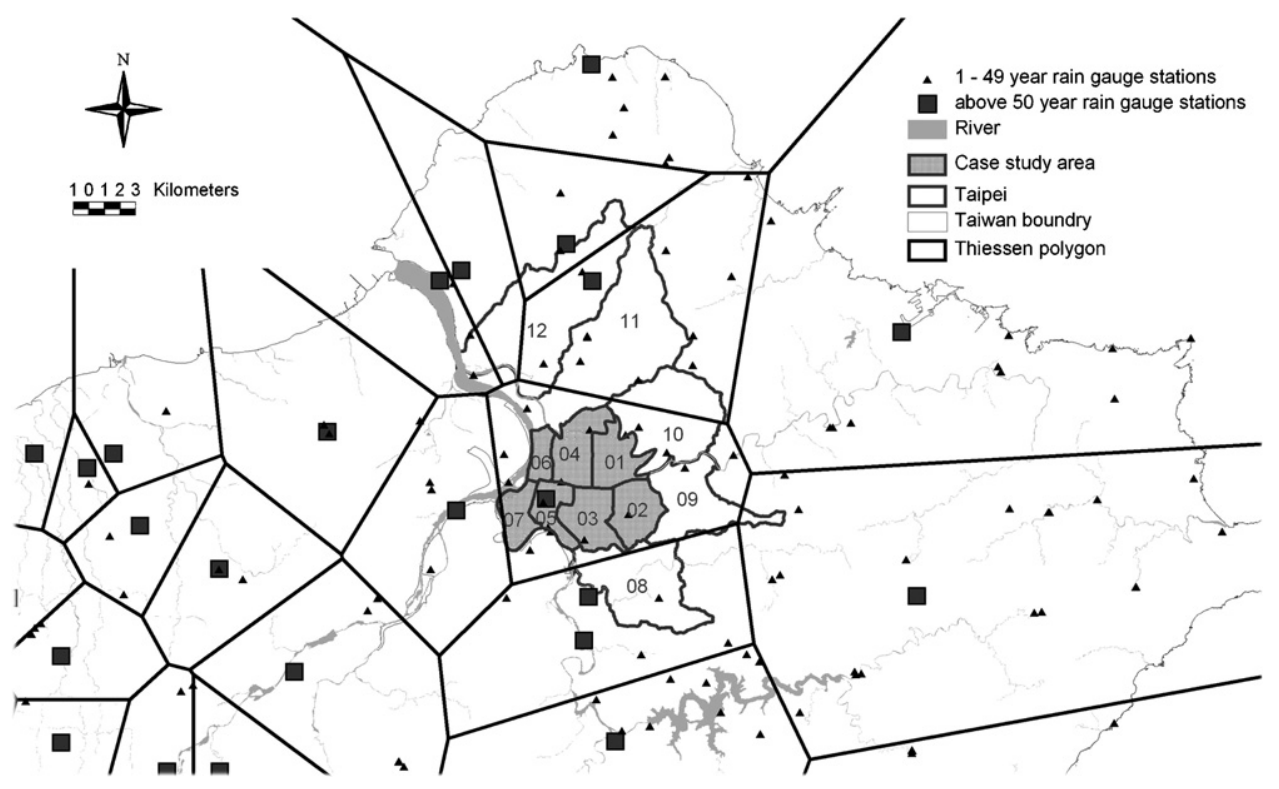

Fig. 4. Control area of rain gauge stations-Thiessen Polygon. 


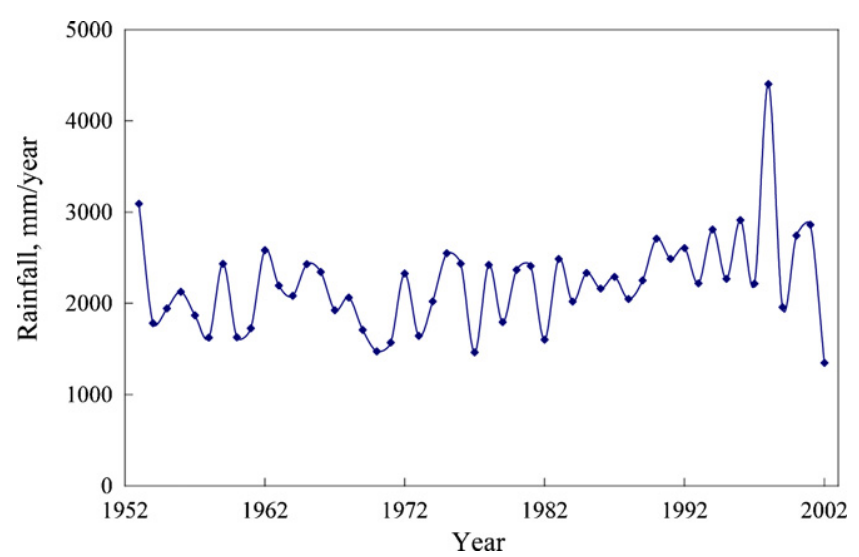

Fig. 5. Mean annual rainfall in Taipei.

for $20 \%$ of this daily water use, which is 501 . The toilet flushing water demand per day per building in the study area is equal to the product of average person per building and flushing water consumption per capita per day and was estimated for the study area to be $1.07 \mathrm{~m}^{3} /$ day.

\section{Results and discussions}

The historical rainfall records and different design storage capacities were fed into the established simulation model for water supply evaluation. Annual deficit rates were used as an index for system evaluations. The resulting deficit rates under each specified design storage sizes are displayed as PDF of some probability distribution. The probabilistic relationships between design storages and corresponding deficit rates will resemble to those. There are two probabilistic distributions shown in Fig. 2: one for the deficit rate under specific design storage, and the other for the storages relative to a fixed design failure level (deficit rates). These relationships can be better described from two different perspectives as follows:

\subsection{The probability distribution of the deficit rate under a specific storage size}

The demand-supply relationships under different design storages were simulated using the historical rainfall data and the established annual simulation model. As the rainfall input is a random process, there exists some probability distribution in the deficit rates under specific design storages. Normal distribution, one of the most commonly observed natural processes, is also the starting point for modeling this deficit rate distribution in some

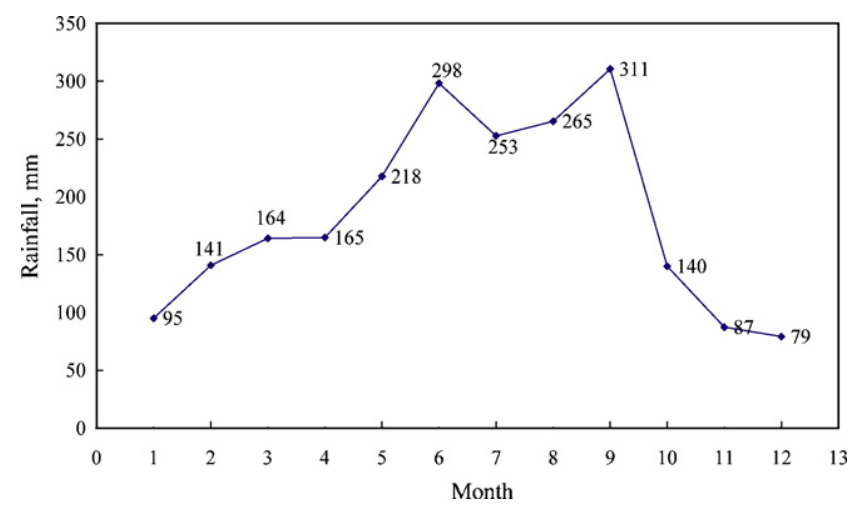

Fig. 6. Mean monthly rainfall in Taipei.
Table 2

Distribution fittings for deficit rate at specific design storage.

\begin{tabular}{rlll}
\hline $\begin{array}{l}\text { RHS storage } \\
\text { size }\left(\mathrm{m}^{3}\right)\end{array}$ & Deficit rate & & $\begin{array}{l}\text { Goodness-of-fit } \\
\text { test } P \text {-value }\end{array}$ \\
\cline { 2 - 3 } & Mean $(\mu)$ & Std. dev. $(\sigma)$ & \\
\hline 1 & 0.65 & 0.04 & 0.50 \\
5 & 0.50 & 0.06 & 0.99 \\
10 & 0.42 & 0.08 & 0.93 \\
20 & 0.34 & 0.09 & 0.62 \\
50 & 0.26 & 0.10 & 0.87 \\
60 & 0.24 & 0.11 & 0.22 \\
100 & 0.22 & 0.11 & 0.58 \\
150 & 0.22 & 0.11 & 0.58 \\
\hline
\end{tabular}

previous studies (Rahman and Yusuf, 2000; Xu, 2005). Normal distribution curves were fitted to the resulting deficit data to describe its probabilistic characteristics in this study. Chi-square test was used to examine the goodness-of-fit of these distribution fittings. Some results of distribution fittings are listed in Table 2 for storage sizes of $1,5,10,20,50,60,100$ and $150 \mathrm{~m}^{3}$. As shown in the table, all the distribution fittings significantly passed the goodness-of-fit test.

The fitted PDFs were shown in Fig. 7. It was observed from the figure and Table 2 that the average water supply deficit, which may be taken as an effectiveness index of the RHS, does decrease as the design storage gets bigger. But it should also be noted that the variations of deficit rate also become a little wider.

\subsection{The storage-deficit relationships at specific exceedance probability}

The fitted distributions as shown in Table 2 and Fig. 7 can be used to follow the process described in Fig. 2(b) through (c). For specific design storage, the deficit rates corresponding to designed exceedance probabilities were estimated by integrating the pdf. The storage-deficit relationships under different exceedance probabilities are shown in Fig. 8. Since exceedance probability is a continuous value between 0 and 1, five relationship curves of EP of $5 \%, 10 \%, 50 \%$, $90 \%$ and $95 \%$ are shown, respectively, in Fig. 8. If the design failure level is set as 0.5 , the relationship between storage and deficit rate can be depicted as the curve of triangle symbol $(E P=50 \%)$ shown in Fig. 8. If the smaller sampling interval (e.g. $1 \mathrm{~m}^{3}$ ) is used, the pdf curves in Fig. 8 can be expanded into a probability density surface as shown in Fig. 9. Fig. 9 shows a more comprehensive view of the storage-deficit relationships. Fig. 8 is actually a sample presentation of the projected front view of Fig. 9.

The variations of deficit rate increase as the storage size increases. It is also observed in Figs. 8 and 9 that the effect of improvements in reducing the deficit rate from bigger design storages diminish and approach to zero as the storage size becomes

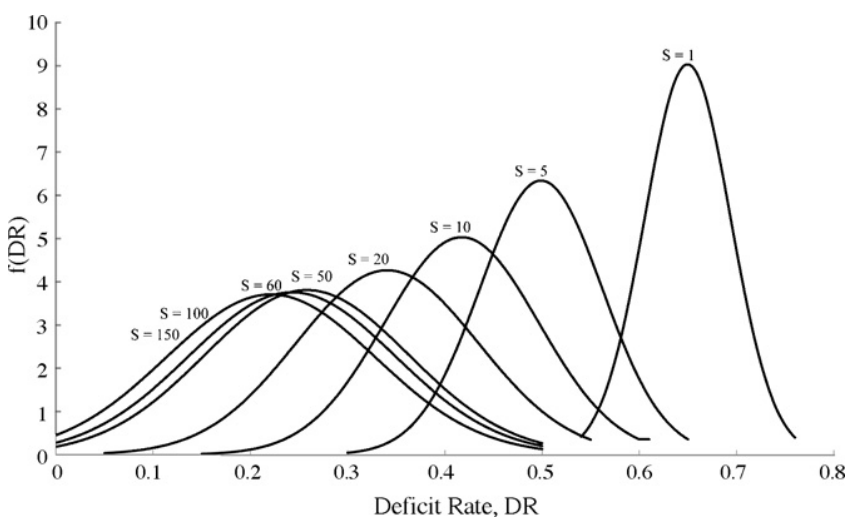

Fig. 7. Fitted pdfs of deficit rate distribution under different design storages. 


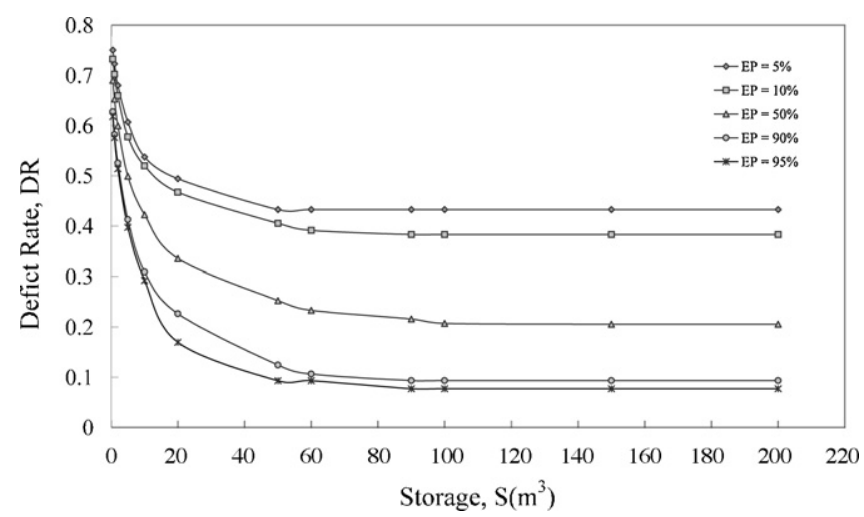

Fig. 8. Storage-deficit rate relationships.

larger than $90 \mathrm{~m}^{3}$. This ceiling shows that there is maximum water availability due to local hydrological limitations and set an upper bound on the water supply improvement by RHS.

It can be observed from Fig. 8 that the economic efficiency, the improvement that an unit increase of storage capacity can achieve, for RHS water supply improvement diminishes with the design storage. This will also help the regional water planners to choose the appropriate design size for their specific circumstances. Although the water supply will increase and the deficit rate will decrease when a larger storage design is used, the cost of the storage will also increase. A suitable design will be the one that balances the rain water capture capacity to reduce the deficit rate and the cost of the RHS installation capitals.

This goodness-of-fit test should be done if this methodology is to be carried out at other sites. Some other distribution should be studied if the goodness-of-fit test for normal distribution fitting fails. Some bivariate probability distribution may exist among deficit rate and design storage size (as shown in Fig. 9). Since the design storage sizes in this study are not physically random variables but pre-defined values in the simulation, and the main objective of this study is to establish a methodology to derive the probabilistic relationship from storage capacities and deficit rates as references to RHS storage design, so no further bivariate study using tool like the Mardia test (Mardia, 1970) was done in this study.

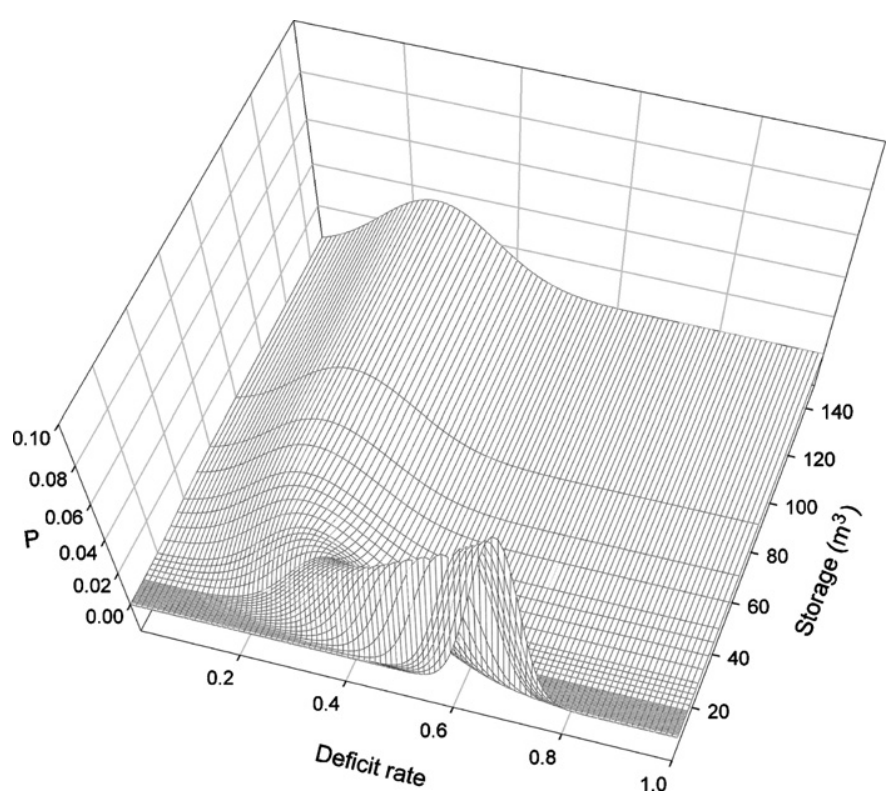

Fig. 9. Probabilistic density surfaces of storage capacities and deficit rates.

\section{Conclusions}

The EP curves describing the continuous relationships between storage capacities and deficit rates were developed in this paper for describing the probabilistic relationships between storages and deficit rates. Not like a single or limited number of probability curves describing the deficit characteristics of a RHS at some specific design storages, the result of this study provides a holistic view of the risk involved in RHS planning and design. The uncertainties characteristics between design storage and the deficit can be more understood through this study on the probabilistic relationships between storage capacities and deficit rates. The developed knowledge can improve the storage capacity design effectiveness for RHS. The fitted probability density function was transformed into exceedance probability (EP) curve for reliability evaluations on RHS designs. A more effective RHS design may be achieved and relieve the regional water supply pressure.

\section{References}

Akintug B, Rasmussen PF. A Markov switching model for annual hydrologic time series. Water Resour Res 2005;41(9).

Becker M, Raasch U. Sustainable stormwater concepts as an essential instrument for river basin management. Water Sci Technol 2003;48(10):25-32.

Dept. of Land. Land statistics yearbook. Taipei, Taiwan; 2005 (in Chinese).

Handia L, Tembo JM, Mwiindwa C. Potential of rainwater harvesting in urban Zambia. Phys Chem Earth 2003;28(20-27):893-6.

Hatibu N, Mahoo H. Rainwater harvesting technologies for agricultural production: a case for Dodoma, Tanzania. Conservation tillage with animal traction. Harare Zimbabwe; 1999, p. 161-171.

Hwang GS, Shieh JD, Chen JC, Fu MT, Hwang PJ. Domestic water conservation management. Sustainable industry development biweekly; 2003 (in Chinese, with English abstract).

Jenkins MW, Lund JR. Integrating yield and shortage management under multiple uncertainties. J Water Resour Plan Manage 2000;126(5):288-97.

Kumar R, Singh RD, Sharma KD. Water resources of India. Curr Sci 2005;89(5):794-811.

Li FR, Cook S, Geballe GT, Burch WR. Rainwater harvesting agriculture: an integrated system for water management on rainfed land in China's semiarid areas. Ambio 2000;29(8):477-83.

Liaw $\mathrm{CH}$, Tsai YL. Optimum storage volume of rooftop rain water harvesting systems for domestic use. J Am Water Resour Assoc 2004;40(4):901-12.

Machiwal D, Jha MK, Singh PK, Mahnot SC, Gupta A. Planning and design of cost-effective water harvesting structures for efficient utilization of scarce water resources in semi-arid regions of Rajasthan, India. Water Resour Manage 2004;18(3):219-35.

Mardia KV. Measures of multivariate skewness and kurtosis with applications. Biometrika 1970;57(3):519-30.

Motsi KE, Chuma E, Mukamuri BB. Rainwater harvesting for sustainable agriculture in communal lands of Zimbabwe. Phys Chem Earth 2004;29(15-18):1069-73.

Nandalal KDW, Sakthivadivel R. Planning and management of a complex water resource system: case of Samanalawewa and Udawalawe reservoirs in the Walawe river, Sri Lanka. Agric Water Manage 2002;57(3):207-21.

Negri DH, Gollehon NR, Aillery MP. The effects of climatic variability on US irrigation adoption. Clim Change 2005;69(2-3):299-323.

Ngigi SN, Savenije HHG, Thome JN, Rockstrom J, DeVries F. Agro-hydrological evaluation of on-farm rainwater storage systems for supplemental irrigation in Laikipia district, Kenya. Agric Water Manage 2005;73(1):21-41.

Panigrahi B, Panda SN, Agrawal A. Water balance simulation and economic analysis for optimal size of on-farm reservoir. Water Resour Manage 2005;19(3):233-50.

Panigrahi B, Panda SN, Mal BC. Rainwater conservation and recycling by optimal size on-farm reservoir. Resour Conserv Recycl 2007;50(4):459-74.

Qian SS, Schulaman A, Koplos J, Kotros A, Kellar P. A hierarchical modeling approach for estimating national distributions of chemicals in public drinking water systems. Environ Sci Technol 2004;38(4):1176-82.

Rahman M, Yusuf FUAMS. Rainwater harvesting and the reliability concept. In: Proceedings of the 8th ASCE specialty conf. on probabilistic mechanics and structural reliability; 2000.

Rajasekaram V, Simonovic SP, Nandalal KDW. Computer support for implementation of a systemic approach to water conflict resolution. Water Int 2003;28(4):454-66.

Srivastava RC. Methodology for design of water harvesting system for high rainfall areas. Agric Water Manage 2001;47(1):37-53.

Surendran S, Tanyimboh TT, Tabesh M. Peaking demand factor-based reliability analysis of water distribution systems. Adv Eng Software 2005;36(11-12):789-96.

Thomas T. Domestic water supply using rainwater harvesting. Build Res Inform 1998;26(2):94-101.

Wei H, Li JL, Liang TG. Study on the estimation of precipitation resources for rainwater harvesting agriculture in semi-arid land of China. Agric Water Manage 2005;71(1):33-45. 
Yue S, Wang CY. Possible regional probability distribution type of Canadian annual streamflow by L-moments. Water Resour Manage 2004;18(5):425-38.

Xu C, Goulter IC. Reliability based optimal design of water distribution networks. ASCE J Water Res Plan Manage 1999;125(6):352-62.
Xu ZS. An overview of methods for determining OWA weights. Int J Intell Syst 2005;20(8):843-65.

Zhang XY, Cai HJ. The development of the model to simulate and optimize the rainwater-harvesting system for irrigation. J Exp Bot 2003;54:45-6. 